\title{
EMPRESAS AGRÍCOLAS E DESENVOLVIMENTO ECONÔMICO: POTENCIALIDADES DA PROVÍNCIA DO HUAMBO, EM ANGOLA
}

Luís Miguel Pacheco*

Ezequiel Lote**

Fernando Oliveira Tavares***

RESUMO: Este artigo tem como objetivos avaliar as potencialidades das Empresas Agrícolas Empresariais e Familiares no desenvolvimento da província do Huambo (Angola) e procurar fundamentos que reforcem a ideia da contribuição que a agricultura pode dar ao crescimento e desenvolvimento econômico e, em particular, à diversificação da economia da província. É realizada uma revisão da literatura sobre a relação entre o setor agrícola e o desenvolvimento econômico, sendo igualmente caracterizada a situação atual de Angola e da província do Huambo em termos agrícolas. Com base na população alvo das empresas agrícolas empresariais e empresas agrícolas familiares foi aplicado um questionário junto aos responsáveis dessas entidades, sendo analisados estatisticamente, respectivamente, 197 e 300 inquéritos válidos. Os resultados evidenciam algumas das principais fragilidades da agricultura na província, nomeadamente, a baixa produtividade, explicada pelo baixo índice de mecanização, pela fraca utilização de fertilizantes, pela dependência das chuvas e pelas dificuldades de acesso a apoios financeiros e técnicos. São igualmente identificadas algumas diferenças significativas entre os dois tipos de entidades inquiridas, as quais motivam um conjunto de recomendações e a adoção de políticas diferenciadas.

PALAVRAS-CHAVE: África; Economia rural; Agricultura familiar; Política agrícola; Modernização da agricultura.

\section{AGRICULTURAL COMPANIES AND ECONOMIC DEVELOPMENT: POTENTIALITIES OF THE HUAMBO PROVINCE, ANGOLA}

ABSTRACT: The potentialities of Entrepeneur and Familiar Agricultural Companies

\footnotetext{
${ }^{*}$ Doutorado em Economia; Professor Associado na Universidade Portucalense - Porto, Portugal; Pesquisador do REMIT (Research on Economics, Management and Information Technologies) e do IJP (Instituto Jurídico Portucalense).E-mail: luisp@upt.pt

${ }^{* *}$ Mestre em Gestão, Chefe de Gabinete de Estudos, Planeamento e Estatística - Universidade José Eduardo dos Santos - Huambo, Angola

*** Doutorado em Gestão Industrial; Professor Auxiliar na Universidade Portucalense - Porto, Portugal; Pesquisador do REMIT (Research on Economics, Management and Information Technologies) e do IJP (Instituto Jurídico Portucalense).
} 
for the development of the Huambo Province in Angola are provided. Current study analyzes factors that strengthen the idea that agriculture triggers economic growth and development, coupled to the diversification of the province's economy. A review of the literature has been undertaken between the agricultural sector and economic development by characterizing current situation in Angola and the Huambo province in agricultural terms. Foregrounded on the target population of entrepeneur and familiar agricultural companies, a questionnaire was applied with the authorities of the companies and the 197 and 300 valid responses were statistically analyzed. Results showed the province's main agricultural weaknesses, or rather, low productivity due to low mechanization rates, low use of fertilizers, dependence on rain and difficulties in accessing financial and technical support. There are some significant differences between the two types of companies, which triggered a set of recommendations and adoption of differentiated policies.

KEY WORDS: Africa; Rural economy; Family agriculture; Agricultural policy; Modernization of agriculture.

\section{INTRODUÇÃO}

O setor da agricultura constitui uma mola impulsionadora para o crescimento e desenvolvimento local, regional e nacional, no entanto, é necessária a participação de outros setores como a indústria, o comércio, os transportes e os bancos que, de forma interligada, propiciem um ambiente favorável. Por sua vez, o setor da agricultura, por ser extremamente relevante em termos de população empregada, constitui um elemento indispensável para a redução da taxa de desemprego em países que lidam com dificuldades na ocupação da mão de obra, como é a maioria dos países africanos.

Com este artigo pretende-se saber até que ponto as empresas agrícolas da província do Huambo, em Angola, são relevantes para o crescimento e desenvolvimento da província. Existe pouca ou nenhuma informação sobre este tema, pelo que este trabalho exploratório pretende proporcionar um ponto de partida para maior conhecimento das potencialidades das empresas agrícolas no desenvolvimento da província. Diante do contexto de queda do preço do barril de petróleo, o Estado angolano tem procurado a diversificação da economia, 
com forte inclinação para o domínio agrícola por ser um setor que acolhe grande massa populacional. O trabalho de pesquisa aqui apresentado é inédito e oferece contributos relevantes ao revelar a realidade das Empresas Agrícolas Empresarias (EAE) e Empresas Agrícolas Familiares (EAF) da província do Huambo, mostrando de que modo aquelas poderão ser capazes de promover o desenvolvimento. No âmbito do artigo, é efetuado um questionário aos responsáveis das EAE e das EAF, sendo analisados estatisticamente, respectivamente, 197 e 300 inquéritos válidos.

Após esta introdução, a segunda seção resume a temática das teorias de crescimento e desenvolvimento e sua relação com o setor agrícola. Na mesma seção, é abordada a questão do desenvolvimento de Angola em termos agrícolas, com um enfoque especial na província do Huambo. A terceira seção compreende a metodologia do trabalho de investigação realizado e na quarta são analisados estatisticamente os resultados do inquérito, realizando-se o cruzamento de algumas variáveis comuns a ambas as empresas. $\mathrm{O}$ artigo culmina com a discussão dos resultados, onde se analisa a sustentabilidade da questão colocada como base de estudo deste trabalho científico e se apresentam algumas limitações.

\section{FUNDAMENTAÇÃO TEÓRICA}

\subsection{DESENVOLVIMENTO ECONÔMICO E O SETOR AGRÍCOLA}

Desde os economistas clássicos do século XVIII que inúmeros autores desenvolveram teorias sobre o papel da agricultura no crescimento e desenvolvimento econômicos. Entre as diferentes abordagens, existe polêmica entre os economistas clássicos com relação a esta questão (AVELÃS, 1999), nomeadamente, acerca do papel da terra no crescimento econômico e dos limites resultantes da lei dos rendimentos decrescentes. No decorrer dos anos 50 do século passado, a corrente dualista centrava a sua análise no atraso relativo da agricultura e nas dificuldades que teria em incorporar as modernas técnicas de produção (GARCIA, 1990). Lewis (1954) consolidou a visão clássica de economia dualista, que evoluiu para o modelo de migração rural-urbana de Harris e Todaro (1970). De acordo com Nojima (2008), 
o cenário elaborado por Lewis vem do reconhecimento de que em zonas altamente populosas do planeta, como Ásia e África, há excesso de mão de obra, dedicada a atividades de baixíssima produtividade, sendo as remunerações aí auferidas apenas suficientes para assegurar a sobrevivência.

As teorias desenvolvidas, para além de tenderem a subestimar o papel da agricultura, têm certa validade numa determinada época e lugar, não podendo constituir explicações gerais do processo de desenvolvimento econômico. Gerry (2002) enfatiza o contributo do setor como principal fonte de emprego em comunidades sobretudo rurais, continuando a ser o setor socialmente mais relevante em muitos países. Cunguara et al. (2013) enfatizam que o aumento da produção agrícola (e não agrícola) está condicionado aos níveis de educação da população (capital humano), acesso aos serviços públicos (capital social) e infraestruturas (capital físico). Por ser o maior setor nos países em desenvolvimento, a agricultura tem papel importante em prover recursos para o desenvolvimento global da economia. Porém, a forte exploração da agricultura antes de importantes investimentos no seu desenvolvimento pode ser fatal, como muitas vezes tem sido o caso de África (BANCO MUNDIAL, 2008).

A agricultura tem papel relevante no processo de desenvolvimento econômico, concretamente na dinamização da indústria, do comércio e dos serviços, por meio dos efeitos que mantém com o resto da economia (LUCENA; SOUZA, 2001; MOSCA, 2008; PINHEL, 2012). O investimento nas infraestruturas, na tecnologia e no capital humano e, ao mesmo tempo, a melhoria das políticas que orientam o setor agrário, são sem dúvida contribuições para o crescimento da produtividade agrícola, que em Angola é inferior à média africana (PACHECO; CARVALHO; HENRIQUES, 2011). Os países com níveis baixos de desenvolvimento apresentam muita dependência da agricultura no que diz respeito ao emprego, pelo que o desenvolvimento sustentável exige alternativas tecnológicas intensivas em mão de obra. Nessas condições, a difusão de tecnologias agrícolas intensivas em capital certamente provocaria um agravamento dos desequilíbrios sociais (ROMEIRO, 1996). É pois importante que a introdução do referido processo seja feita de forma gradual, respeitando os valores individuais de cada povo.

O papel da agricultura no crescimento e desenvolvimento dos países foi 
colocado em dúvida, persistindo a ideia de que quanto mais desenvolvido fosse um país menor seria a importância daquele setor. Johnston e Mellor (1961) e Shultz (1964) contrariaram esta tendência, defendendo que os países pobres que pretendam crescer podem potenciar o crescimento econômico por meio da agricultura desde que invistam e modernizem novas técnicas conforme a dos países desenvolvidos. Para Shultz (1964), o raciocínio era que o infortúnio se devia à baixa produtividade marginal dos fatores, sobretudo os fatores tradicionais terra e trabalho, o que não estimula o reinvestimento na produção por parte dos agricultores. Na mesma linha de pensamento de Shultz (1964), os sucessivos "Relatórios sobre Desenvolvimento Humano" do Programa das Nações Unidas para o Desenvolvimento (PNUD) enfatizam sucessivamente o papel que o setor da agricultura poderá ter na redução da pobreza, na estabilidade social e no desenvolvimento humano em geral, fatos bem patentes nos recentemente definidos "Objetivos de Desenvolvimento Sustentável".

Nos países predominantemente agrícolas, a agricultura e a indústria poderão funcionar como aceleradores do crescimento econômico, originando forte impacto na redução da pobreza e provendo a segurança alimentar. No entanto, a dependência da agricultura para o crescimento requer uma revolução da produtividade agrícola de pequena escala pois, no caso angolano, a maior parte dos aumentos recentes na produção são fundamentalmente resultado do aumento da área cultivada (PACHECO et al., 2011). É neste universo que a agricultura familiar aponta caminhos alternativos pois, apesar de não alcançar os resultados de produtividade esperados no mercado capitalista, apresenta-se como uma prática eficaz para a economia solidária, inclusão social, diminuição das desigualdades e para o desenvolvimento rural (CARVALHO; SANTOS; CARVALHO, 2015).

Numa grande parte dos países africanos, principalmente aqueles produtores de petróleo, a agricultura é mencionada como recurso de importância capital apenas no discurso político, pois a economia é dominada pelo petróleo (PACHECO et al., 2011). A atenção devotada à agricultura, evidenciada por parte de alguns Estados africanos nas suas despesas públicas correntes e de investimento, não foi acompanhada por uma adequada gestão de um sistema de preços e salários e outros mecanismos macroeconômicos. Estes fatores influenciaram de forma negativa o setor privado, dificultando ou mesmo impedindo a reprodução dos ciclos produtivos. A sobrevivência por parte de alguma população deveu-se às produções em pequena 
escala, enfrentando inúmeros problemas, tais como a ausência de infraestruturas e a possibilidade de substituição ou reparação de equipamentos.

Segundo a Organização das Nações Unidas para a Alimentação e Agricultura (FAO, 2014), a agricultura familiar, que inclui todas as atividades familiares (agricultura, atividade florestal, pesca, pastoril), está fortemente ligada à segurança alimentar dos países. De acordo com Fischer, Marini e Filippim (2015) e Baiardi e Alencar (2014), a agricultura familiar tem especificidades que a distinguem de outras empresas familiares, sendo a principal a estabilidade, pois é menos vulnerável a conjunturas e ciclos econômicos. A "revolução verde", ao contrário de promover a mecanização e o êxodo rural, incentiva a utilização de técnicas modernas de cultivo (por exemplo, a utilização de fertilizantes e de sementes melhoradas), compatíveis com uma economia agrícola familiar, de pequena escala, havendo ainda um longo caminho a percorrer por aquela "revolução" na África (GUANZIROLI; GUANZIROLI, 2015). Perante alguns avanços, é da responsabilidade dos governos africanos tirar proveito deste período de sucesso do continente, com vista a enfrentar os dramas que ainda persistem, como a insegurança alimentar, a desnutrição e a fome.

\subsection{SITUAÇÃO DO SETOR AGRÍCOLA EM ANGOLA}

A população angolana dedica-se essencialmente ao cultivo da terra como fonte da sua subsistência e grande parte das baixas rendas obtidas pelas famílias é obtida no comércio ao longo das estradas, onde se praticam preços muito baixos comparativamente ao mercado convencional. Em algumas regiões de Angola, sobretudo no norte, grande parte dos camponeses está organizada em associações, cujas quotizações visam à manutenção das vias de acesso da estrada principal às propriedades. Contudo, a pobreza extrema a que esses membros estão votados dificulta que consigam manter alguma regularidade no pagamento das quotas (CORIGE; HENRIQUES; CARVALHO, 2013).

Com a independência, a produção agrícola começou a declinar a partir de 1974/1975. O conflito pós-independência, que durou 27 anos, provocou a destruição de infraestruturas, colocando Angola, que era um país autossuficiente na generalidade dos alimentos antes do conflito armado, numa situação de dependência externa. O conjunto de políticas que foram surgindo para fazer face ao 
declínio da produção agrícola foi ineficaz devido às constantes distorções de caráter macroeconômico, provocadas pela ausência de estímulos no setor agrícola, preços desajustados, ausência de registro de propriedades e legislação para proteção dos agricultores. Com o evoluir do conflito, assistiu-se à emigração do campo para os grandes centros urbanos e à fuga de quadros qualificados que detinham a rede de comercialização dos produtos agropecuários, agravando-se os baixos índices de formação profissional e desaparecendo o apoio técnico e às infraestruturas (PAIN; ARRUDA, 2009).

Segundo dados do Ministério da Agricultura, do Desenvolvimento Rural e das Pescas (MADRP), o setor agrícola angolano representa cerca de 11\% do PIB, sendo predominantemente caracterizado por empresas familiares que praticamente representam a totalidade das unidades produtivas (mais de 99\%), cultivando áreas reduzidas e responsáveis pela grande maioria da produção. As empresas agrícolas são simplesmente formadas pelas famílias que procuram produzir para o sustento das necessidades do seu agregado e algum excedente para comercialização (MBOMBA; HENRIQUES; REGO; CARVALHO, 2009; CARVALHO et al., 2015).

Os dois tipos de unidades produtivas que iremos aqui considerar Empresas Agrícolas Empresariais (EAE) e Empresas Agrícolas Familiares (EAF) - estão fundamentalmente concentradas nas províncias de Huambo, Huila, Bie, Kuanza Sul, Uige e Benguela. As parcelas de terra são preparadas em cada época para o cultivo de diversos produtos, melhor adaptados às condições de clima e solo, nomeadamente, cereais, raízes e tubérculos, leguminosas e oleaginosas, frutas, hortícolas e café. Note-se que as quantidades produzidas provenientes das EAF são superiores às das EAE, dada a forte preponderância daquelas. Por outro lado, o lugar cimeiro ocupado pelos cereais justifica-se pelo fato de grande parte da população angolana ter no milho a base da sua alimentação.

Quanto à preparação das terras para as épocas agrícolas, o MADRP participa por meio do Instituto de Desenvolvimento Agrário (IDA) que é um órgão tutelado pelo Ministério e a quem cabe a responsabilidade de materializar ações para a reabilitação e o desenvolvimento das comunidades rurais. 


\subsection{SITUAÇÃO DO SETOR AGRÍCOLA NA PROVÍNCIA DO HUAMBO}

A província do Huambo tem um relevo acidentado, com uma altitude média acima dos 2.000 metros, possui grandes recursos hidrográficos, com um clima úmido e seco e com a temperatura média durante o ano que oscila entre os $15^{\circ} \mathrm{C}$ e os $20^{\circ} \mathrm{C}$, com duas estações, sendo a mais longa a chuvosa e a mais curta a estação seca. Constitui uma das províncias angolanas com maior densidade populacional, pois apesar de representar menos de 3\% da área do país, nela reside cerca de $11 \%$ da população. Portanto, tal significa que há forte pressão para a produção e disponibilização de bens alimentares.

Com o início da guerra civil, Angola viu-se privada em todos os setores dos seus melhores técnicos não nacionais. Por exemplo, o número de agrônomos e veterinários passou a ser irrisório, na medida em que o centro universitário do Huambo era coordenado por portugueses até a data da independência (PACHECO et al., 2011). Como a política do partido único naquele momento não encorajava a iniciativa privada, e menos a familiar, as áreas efetivamente cultiváveis foram drasticamente reduzidas, aumentando as terras vagas.

No caso concreto da província do Huambo, todos os anos, antes do início da época agrícola, o IDA prepara a época juntamente com os seus parceiros, nomeadamente, Empresas Agrícolas Familiares (EAF), Empresas Agrícolas Empresariais (EAE), Associações e Cooperativas. O IDA, no âmbito das suas atribuições, apoia técnica e materialmente aqueles parceiros, com meios e equipamentos (Tabela 1).

Tabela 1. Agricultores envolvidos (2009-2014)

(Continua)

\begin{tabular}{|c|c|c|c|c|c|c|}
\hline \multirow{2}{*}{$\begin{array}{c}\text { Campanha } \\
\text { agrícola }\end{array}$} & \multirow{2}{*}{$\begin{array}{c}\quad \text { n. }^{\mathrm{o}} \\
\text { aprox. de } \\
\text { habitantes }\end{array}$} & \multicolumn{2}{|c|}{$\begin{array}{l}\text { n. }{ }^{\circ} \text { de pequenos } \\
\text { agricultores }\end{array}$} & \multirow[b]{2}{*}{ Associações } & \multirow[b]{2}{*}{ Cooperativas } & \multirow{2}{*}{$\begin{array}{c}\text { Produção } \\
\text { (Ton) }\end{array}$} \\
\hline & & $\begin{array}{c}\text { Existência } \\
\text { geral }\end{array}$ & $\begin{array}{l}\text { Com } \\
\text { assistência } \\
\text { técnica }\end{array}$ & & & \\
\hline 2009-2010 & 2.486 .236 & 1201 & 675 & 710 & 122 & 291.946 \\
\hline 2010-2011 & 2.435 .739 & 1548 & 572 & 813 & 154 & 1.101 .170 \\
\hline
\end{tabular}


(Conclusão)

\begin{tabular}{|c|c|c|c|c|c|c|}
\hline \multirow{2}{*}{$\begin{array}{l}\text { Campanha } \\
\text { agrícola }\end{array}$} & \multirow{2}{*}{$\begin{array}{c}\quad \text { n. }^{\mathrm{o}} \\
\text { aprox. de } \\
\text { habitantes }\end{array}$} & \multicolumn{2}{|c|}{$\begin{array}{c}\text { n. }{ }^{\circ} \text { de pequenos } \\
\text { agricultores }\end{array}$} & \multirow[b]{2}{*}{ Associações } & \multirow[b]{2}{*}{ Cooperativas } & \multirow{2}{*}{$\begin{array}{l}\text { Produção } \\
\text { (Ton) }\end{array}$} \\
\hline & & $\begin{array}{l}\text { Existência } \\
\text { geral }\end{array}$ & $\begin{array}{l}\text { Com } \\
\text { assistência } \\
\text { técnica }\end{array}$ & & & \\
\hline $2012-2013$ & 2.426 .340 & 1783 & 961 & 757 & 155 & 1.163 .952 \\
\hline 2013-2014 & 2.470 .487 & 1511 & 736 & 851 & 211 & 1.057 .557 \\
\hline
\end{tabular}

Fonte: Relatório da Direção Provincial da Agricultura - Instituto de Desenvolvimento Agrário 20092013.

Nota: Não estão disponíveis dados para a campanha agrícola de 2011-2012.

As EAF são tipicamente constituídas pelas famílias, daí o seu elevado número e área cultivada. Por outro lado, as EAE são constituídas pelas Empresas Agrícolas, estas em muito menor número na província e no país em geral. A existência em pequena escala das EAE é explicada pelos elevados custos de produção, que desincentivam o seu surgimento.

O IDA prepara a terra para cada campanha agrícola, auxiliando neste processo produtivo as EAE. Por sua vez, as famílias também preparam terras, por meio de processos manuais e com alguma ajuda de tração animal, juntando-se assim às terras preparadas e provenientes do IDA. Algumas associações e cooperativas, pela sua organização funcional, possuem tratores e outros equipamentos que intervêm no processo de produção.

Apesar das EAF da província do Huambo utilizarem meios manuais e/ou o auxílio em determinadas campanhas agrícolas de tração animal na preparação da terra, a quantidade de terra preparada tem sido satisfatória. À semelhança do que acontece em todo o território nacional, na província do Huambo, embora os dados apresentados estejam condensados, o setor que mais produz em termos quantitativos é o constituído pelas EAF, pois existe elevado número de famílias envolvidas nos processos agrícolas.

A quantidade de hectares preparada com o auxílio de máquinas, por época agrícola, nas últimas décadas, aumentou de forma exponencial. No entanto, representa uma ínfima parte da superfície total preparada (Tabela 2). Com a 
consolidação da paz em Angola, e em particular na província do Huambo, muitos campos de cultivo foram reabertos pois tinham sido minados no período de guerra. Com os efeitos da paz, muitas famílias que viviam nas zonas urbanas foram incentivadas a regressar às suas zonas de origem, podendo desta forma passar a viver de produtos provenientes do campo, provocando aumento nos níveis de superfície de zona cultivada conforme se pode constatar na Tabela 2.

Tabela 2. Superfície de terra preparada (2009-2014)

\begin{tabular}{c|c|c|c|c|c|c}
\hline \multirow{2}{*}{$\begin{array}{c}\text { Campanha } \\
\text { agrícola }\end{array}$} & $\begin{array}{c}|c| \\
\text { puperfície de terra } \\
\text { preparada com auxílio de } \\
\text { máquinas }\end{array}$ & $\begin{array}{c}\text { Terra } \\
\text { preparada } \\
\text { com tração } \\
\text { animal (ha) }\end{array}$ & $\begin{array}{c}\text { Terra } \\
\text { preparada } \\
\text { manualmente } \\
\text { (ha) }\end{array}$ & $\begin{array}{c}\text { Total de } \\
\text { superfície } \\
\text { preparada } \\
\text { (em ha) }\end{array}$ & $\begin{array}{c}\text { Rendimento } \\
\text { médio (Ton.) } \\
\text { por ha } \\
\text { cultivado }\end{array}$ \\
\hline $2009-2010$ & 4.000 & 3.122 & 306.293 & 653.476 & 962.891 & 0,30 \\
$2010-2011$ & 5.500 & 6.413 & 113.768 & 852.122 & 972.303 & 1,13 \\
$2012-2013$ & n.d. & 10.268 & 211.153 & 715.290 & 936.711 & 1,24 \\
$2013-2014$ & n.d. & 20.051 & 366.176 & 382.000 & 768.227 & 1,38 \\
\hline
\end{tabular}

Fonte: Relatório da Direção Provincial da Agricultura - Instituto de Desenvolvimento Agrário 20092013.

Nota: Os dados relativos às quantidades produzidas compreendem informação proveniente das EAF, EAE, associações e cooperativas. Não estão disponíveis dados para a campanha agrícola de 2011-2012.

As quantidades produzidas e a produtividade por hectare, por cada campanha agrícola, têm aumentado devido aos apoios que o MADRP presta por meio das direções provinciais da agricultura. Pode-se comprovar este fato tendo em conta o aumento gradual da média de rendimento em tonelada por hectare cultivado (1,38 toneladas por ha, em 2013/14, de acordo com dados da Direção Provincial de Agricultura).

\section{METODOLOGIA}

Para a realização deste trabalho foi identificada como população alvo as EAE e as EAF. A população alvo é assim constituída em função das entidades 
que participam nas campanhas agrícolas organizadas pela Direção Provincial da Agricultura e Desenvolvimento Rural (DPADR).

Fazem parte das EAE as associações e cooperativas agrícolas, legalmente constituídas ou não, e fazem parte das EAF as famílias e pequenos agricultores, apoiados ou não. Todos os participantes integram as duas campanhas agrícolas realizadas na província, conforme é descrito na Tabela 3 apresentada a seguir, com dados para os 11 municípios:

Tabela 3. População que constitui as EAE e as EAF

\begin{tabular}{|c|c|c|c|c|c|c|}
\hline \multirow[t]{2}{*}{ Município } & \multicolumn{3}{|c|}{ Empresas Agrícolas Empresariais } & \multicolumn{3}{|c|}{ Empresas Agrícolas Familiares } \\
\hline & Total & $\begin{array}{l}\% \text { do } \\
\text { total }\end{array}$ & $\begin{array}{l}\text { Unidades } \\
\text { inquiridas }\end{array}$ & Total & $\begin{array}{l}\% \text { do } \\
\text { total }\end{array}$ & $\begin{array}{l}\text { Unidades } \\
\text { inquiridas }\end{array}$ \\
\hline Mungo & 121 & $10,3 \%$ & 20 & 44.916 & $9,2 \%$ & 28 \\
\hline Bailundo & 110 & $9,3 \%$ & 19 & 95.671 & $19,5 \%$ & 59 \\
\hline Londuimbali & 127 & $10,8 \%$ & 21 & 29.315 & $6,0 \%$ & 18 \\
\hline Chicala Cholohanga & 76 & $6,4 \%$ & 13 & 29.674 & $6,1 \%$ & 18 \\
\hline Cachiungo & 189 & $16,0 \%$ & 32 & 42.668 & $8,7 \%$ & 26 \\
\hline Huambo & 116 & $9,8 \%$ & 20 & 111.481 & $22,7 \%$ & 69 \\
\hline Caála & 175 & $14,8 \%$ & 30 & 58.184 & $11,9 \%$ & 36 \\
\hline Ekunha & 64 & $5,4 \%$ & 11 & 27.968 & $5,7 \%$ & 17 \\
\hline Longonjo & 55 & $4,7 \%$ & 9 & 20.426 & $4,2 \%$ & 13 \\
\hline Ukuma & 100 & $8,5 \%$ & 17 & 20.429 & $4,2 \%$ & 13 \\
\hline Chinjenje & 47 & $4,0 \%$ & 8 & 10.108 & $2,1 \%$ & 6 \\
\hline Total & 1180 & & 200 & 490.840 & & 303 \\
\hline
\end{tabular}

Fonte: IDA - Instituto de Desenvolvimento Agrário, afeto à Direção Provincial da Agricultura

Após a identificação da população em estudo, segundo Marôco (2015), é necessário definir como são selecionados os elementos ou objetos que constituem a amostra. Neste trabalho, para as EAE é utilizada a amostragem probabílistica aleatória simples, com uma seleção aleatória dos elementos que constituem a população, mantendo grosso modo os pesos relativos em termos da distribuição por municípios. Relativamente às EAF, e para evitar as grandes deslocações que seria 
necessário efetuar, foi escolhida a amostragem não probabilística acidental, casual ou conveniente, sendo selecionados os elementos da população que constituem objeto de interesse da convicção do inquiridor, embora mantendo-se também aqui a distribuição relativa por municípios (Tabela 3).

Foram elaborados dois inquéritos, um para as EAE e outro para as EAF, onde para além dos dados de identificação dos inquiridos, foram colocadas questões sobre o surgimento, estrutura, organização administrativa e objetivos das entidades, os apoios recebidos e dificuldades encontradas e os principais produtos produzidos e comercializados. Após a realização de um teste dos questionários numa pequena amostra de inquiridos, passou-se à coleta dos dados, que decorreu no período de janeiro a fevereiro de 2015, e da qual resultaram, 197 e 300 questionários válidos, respectivamente, para as EAE e EAF. Os dados do questionário foram tratados com o software SPSS Estatistic 20.

Para além da análise descritiva das respostas dadas pelas EAE e EAF, são pesquisadas questões comuns, tentando descortinar diferenças significativas entre as duas entidades. Para tal, são efetuados testes de igualdade de variâncias (Teste de Levene) e, em função do resultado, verifica-se por meio dos testes-t se existem evidências de diferenças estatisticamente significativas entre as respostas médias dadas pelas duas entidades. Essa evidência é uma questão muito relevante, pois poderá justificar a aplicação de políticas diferenciadas. Na seção seguinte são apresentados os resultados do inquérito realizado junto às EAE e EAF, optando por resumir essa apresentação às principais respostas por motivos de espaço disponível.

\section{RESULTADOS E DISCUSSÃO}

\subsection{EMPRESAS AGRÍCOLAS EMPRESARIAIS}

A grande preocupação das EAE é o aumento do nível de renda dos membros que a constituem. Cerca de $71 \%$ afirmam este objetivo como prioritário, enquanto que $18 \%$ preferem alargar a extensão de terra com vista ao aumento da produção e cerca de $5 \%$ pretendem no futuro ver a EAE transformada numa outra atividade geradora de receitas. Finalmente, $4 \%$ indicaram outros fins e $2 \%$ preferiram não 
dizer nada sobre o conteúdo da pergunta. Em termos de dimensão, 13\% das EAE agregam mais de 501 membros e 21\% congregam menos de 50 membros.

A produção orientada para as famílias e para o mercado constitui o objetivo de 68\% das 197 EAE questionadas, o que significa que as EAE, na sua maior parte, são constituídas por unidades autossuficientes, capazes de destinar parte da produção total para o consumo e parte para o mercado informal. Outras $12 \%$ responderam que, pelas dificuldades que encontram no aumento da produção, é toda destinada para o consumo, enquanto que apenas $5 \%$ orientam a sua atividade produtiva exclusivamente para o mercado formal. Quando se pretendeu saber quais eram as entidades governamentais, ou outras, que apoiavam as $\mathrm{EAE}, 93 \%$, afirmaram que da Unaca (Confederação das Associações de Camponeses e Cooperativas Agropecuárias de Angola) apenas recebiam apoio administrativo e que da DPADR, por meio do IDA, recebiam apoio técnico de forma muito irregular e fertilizantes em quantidade insuficiente para cobrir as áreas de cultivo.

Na escolha do líder para asEAE, um dos critérioséo nível de escolaridade, dada a necessidade de gerir, organizar e manter funcional a organização. Relativamente ao nível acadêmico dos líderes das EAE verifica-se que a maioria possui apenas o nível primário (56\%), surgindo a seguir o nível secundário e, finalmente, o nível médio. Note-se que $10 \%$ dos líderes das EAE nunca frequentaram a escola. Relativamente aos terrenos de onde provêm o sustento da população, grande parte não está inscrito nas Conservatórias de Registro Predial. Nos casos em que o registro já foi efetuado, a iniciativa partiu dos mesmos indivíduos que compõem as EAE (cerca de $11 \%$ ) e em $9 \%$ dos casos foi por iniciativa das autoridades governamentais. Importa mencionar aqui que $74 \%$ dos terrenos não possuem documento de escritura pública que garanta a titularidade da terra ocupada, o que aumenta seriamente o risco de expropriações.

A utilização de meios mecanizados para o cultivo da terra ainda é incipiente, surgindo apenas em $12 \%$ das respostas, o que tem efeitos imediatos na produção. A maioria das EAE utiliza meios manuais (enxada, catana/facão e outros) e em determinadas fases do cultivo incrementam a tração animal, perfazendo $62 \%$ das respostas. Relativamente à questão sobre as fontes de financiamento das EAE, cabe considerar que $89 \%$ dos investimentos realizados têm como fonte os próprios 
membros, com uma representação fraca dos bancos (apenas 3\% das respostas) e de fundos de apoio à agricultura (apenas 5\%). Como veremos, é possivel associar a questão colocada a seguir sobre a satisfação dos inquiridos com os resultados alcançados com esta questão da disponibilidade de fontes de financiamento.

A atividade produtiva agrícola está orientada na sua maioria para o mercado informal, com as opções de produção em função das oscilações em termos de preços dos produtos cultivados. Assim, leguminosas como o feijão constituem a primeira opção de cultivo, considerando o fato do preço no mercado informal para aquele produto situar-se, no momento da elaboração deste trabalho, no intervalo de 1,5 a 3 dólares americanos (USD) por quilo. Seguidamente, o cultivo do milho e de produtos hortícolas ocupa, respetivamente, as segunda e terceira opções. Tendo em consideração que, para a grande maioria dos inquiridos, a produção é feita em função do mercado informal, foi questionado qual o produto mais solicitado pelo mercado. Em resposta a esta questão, o feijão surge em primeiro lugar, seguido de produtos como os hortícolas, a batata e, por fim, o milho.

É preciso reconhecer as dificuldades por que passam os agricultores que constituem as EAE dada a necessidade regular de fortificar os solos com fertilizantes. Refira-se que, apesar de 94\% das EAE afirmarem que utilizam fertilizantes, apenas cerca de $14 \%$ afirmaram que os adquirem nos mercados formais, enquanto que $32 \%$ os adquirem nos mercados informais. Note-se que, menos de 5\% dos inquiridos afirmaram que os fertilizantes foram adquiridos de forma subvencionada pelas autoridades governamentais. A alternativa que os agricultores têm aos fertilizantes químicos serão os adubos orgânicos, conhecidos por $85 \%$ dos inquiridos e utilizados por cerca de $79 \%$ das $\mathrm{EAE}$.

Os inquiridos não estão totalmente satisfeitos com os resultados da sua produção, existindo cerca de $84 \%$ de EAE em que os seus membros se encontram "razoavelmente satisfeitos" e apenas em 11\% estão "muito satisfeitos". Refira-se que, $80 \%$ dos inquiridos consideram a sua produtividade dependente das quedas pluviométricas, o que condiciona o cultivo da terra na segunda época, sob risco de perder parte do capital investido. É de notar que, somente $17 \%$ possuem capacidade para produzir nas duas épocas agrícolas, recorrendo à utilização de valas de irrigação. Em função da dependência das chuvas, os inquiridos afirmam que um dos fatores 
que condiciona a produtividade é a irregularidade pluviométrica que se verifica em determinadas épocas, deixando-os sem alternativas (68\% dos inquiridos indicam a chuva como o principal fator natural que condiciona a produção).

Quando se pesquisaram os fatores não naturais responsáveis pela produção inferior ao desejado, metade dos inquiridos afirma como primeira causa a falta de crédito bancário, surgindo em segundo lugar a falta de matérias-primas, com 32\% das respostas. Podemos afirmar que as duas variáveis se encontram relacionadas, porque a cedência de crédito às EAE aumenta a sua capacidade de aquisição de matériasprimas, essenciais para maior produtividade. Finalmente, quando questionados se a agricultura pode exercer alguma influência no surgimento de novos setores de produção, 94\% dos inquiridos concordaram.

\subsection{EMPRESAS AGRÍCOLAS FAMILIARES}

Relativamente às EAF, o nível de escolaridade dos entrevistados é considerado como baixo, pois $21 \%$ dos inquiridos responderam que nunca estudaram e 37 e $30 \%$ apenas atingiram, respetivamente, os níveis primário e do segundo ciclo. O número de filhos por família é um fator a ter em conta, sabendo que quanto maior é a família, maior será a área de terra necessária para o cultivo. Existe um equilíbrio entre as famílias com até cinco e de cinco a dez filhos, pois 45\% das famílias surgem com menos de cinco filhos, $46 \%$ com cinco a dez filhos e $5 \%$ com mais de dez filhos ( $4 \%$ dos inquiridos não responderam à questão).

$\mathrm{Na}$ questão relativa às outras fontes de emprego para além da agricultura, 88\% afirmaram que não possuem outra fonte alternativa de receitas. A forma mais frequente no que diz respeito à aquisição do campo agrícola é a cedência por herança, que se verifica em $68 \%$ dos casos, seguida pela aquisição, que constitui $24 \%$ dos casos. Relativamente ao destino dado à produção, $45 \%$ responderam que apenas consomem o que produz, 34\% responderam que para além do consumo é capaz de destinar uma parte ao mercado informal e $11 \%$ têm a sua atenção orientada para o mercado informal. O mercado formal é o principal destino de apenas $4 \%$ dos produtores e cerca de $6 \%$ dos inquiridos não responderam à questão.

Quando questionadas relativamente aos apoios recebidos por parte das 
entidades governamentais, 99,7\% das famílias afirmaram que não recebiam qualquer apoio do Estado. Também relativamente à questão da existência de registro dos terrenos, importante para conhecer o grau de segurança das famílias, 92\% dos inquiridos responderam que não possuíam qualquer tipo de registro das suas propriedades. É de destacar que 91\% dos entrevistados realizam a agricultura numa superfície de até 5 hectares de terra explorada, utilizando maioritariamente meios manuais e tração animal. Quase metade dos inquiridos afirma que para o cultivo utiliza a enxada, a catana ou facão e outros meios manuais, perfazendo cerca de $49 \%$ das respostas. Uma porção considerável (33\%) afirma que, para além dos meios manuais de cultivo, utiliza a tração animal durante as duas épocas anuais de cultivo. Quanto ao investimento, os resultados indicam que o mesmo é fruto do esforço dos próprios agricultores que por aquela via procuram incrementar as colheitas, pois $98 \%$ das respostas indicam que os investimentos são financiados com fundos próprios.

Como já foi visto acima, grande parte dos nossos interlocutores procuram retirar da terra o seu sustento. Sendo o milho um alimento característico do povo da região, os resultados mostram que mais da metade dos inquiridos tem como primeira opção de cultivo o milho (69\%), seguida dos produtos hortícolas (14\%) que, para além de terem uma procura considerável no mercado informal, também constituem parte integrante da dieta alimentar. Por último, o feijão (7\%) que, por um lado, serve para consumo e, por outro lado, é fonte de receitas, e outras culturas pouco relevantes (e.g., batata e mandioca). Refira-se que o destino final da maior parte da produção é o autoconsumo, não tendo por finalidade o mercado.

Por forma a manter o ciclo de produção, $77 \%$ das EAF conservam parte da produção obtida de uma determinada época agrícola, utilizando-a como semente para a época agrícola seguinte, enquanto que $11 \%$ aumentam a superfície cultivada dos produtos com maior rentabilidade e 3\% afirmam que nada faz. Os líderes das EAF afirmam que, com vista a garantir o retorno da produção, é necessária a utilização de fertilizantes químicos ou orgânicos, sendo que 77\% utilizam esses aditivos e apenas $8 \%$ não os utilizam por falta de capacidade de aquisição visto que o preço por quilo varia entre os 2 a 3 USD. Cerca de 65\% dos inquiridos adquirem os fertilizantes no mercado informal, o que torna a produção mais onerosa tendo em atenção 
os preços praticados nesses mercados, dada a falta de produção nacional. Apenas 21\% afirmam adquiri-los no mercado formal, cujo preço é semelhante, embora existam maiores garantias de qualidade. É de notar que apenas 1\% respondeu que beneficia de uma subvenção por parte das entidades governamentais na aquisição de fertilizantes, embora de forma irregular, o que é manifestamente insuficiente em função da superfície de terra destinada para o cultivo. Perante o elevado preço dos fertilizantes, procurou-se saber junto dos elementos da amostra se utilizavam fertilizantes orgânicos, verificando-se que $40 \%$ dos inquiridos os utiliza, provenientes fundamentalmente de gado caprino e de aves, por falta de possibilidade de adquirir os fertilizantes químicos. O grau de satisfação das famílias com a atividade agrícola é razoável, se tivermos em atenção que $80 \%$ da amostra confirmam estar satisfeitas com os resultados da produção e $17 \%$ afirmam que os resultados que obtêm da produção são bons e de acordo com as expectativas.

Relativamente à origem da água utilizada na produção agrícola, 55\% das EAF referem que estão exclusivamente dependentes da água das chuvas. Já 41\% referem que, para além das chuvas, têm acesso a valas de irrigação, o que lhes possibilita produzir no período em que as chuvas diminuem ou apresentam alguma irregularidade. Portanto, relativamente aos fatores naturais que condicionam a atividade agrícola, a chuva representa $47 \%$ das preocupações dos entrevistados, tendo 12\% mencionado a seca. É de realçar que 39\% referem que não conseguem distinguir onde residem as dificuldades. No quadro dos fatores não naturais que impedem uma agricultura com melhores resultados, o crédito agrícola é o mais mencionado, com cerca de $66 \%$ das respostas, sendo o segundo maior dilema a disponibilidade de matéria-prima, com apenas 7\% das respostas. Quanto à influência da agricultura no surgimento de outras atividades, 92\% dos entrevistados não têm dúvidas de que a agricultura pode influenciar o surgimento de outros setores produtivos.

\subsection{RELAÇÃO ENTRE AS RESPOSTAS DAS EAE E DAS EAF}

Nesta seção procura-se relacionar as respostas dadas pelas EAE e EAF a questões comuns, tentando descortinar diferenças significativas entre as duas entidades. Na Tabela 4 são apresentados os resultados dos testes de igualdade de 
variâncias (Teste de Levene).

Pela análise dos resultados apresentados na Tabela 4 conclui-se que apenas é possível aceitar a hipótese nula de igualdade de variâncias em duas das questões colocadas no inquérito, nomeadamente, em relação aos destinos principais da produção (autoconsumo e mercado informal) e a última questão sobre se a agricultura poderá constituir um fator potenciador do desenvolvimento econômico pois, tal como esperado, a grande maioria das respostas é afirmativa).

Tabela 4. Teste-t para igualdade de médias

\begin{tabular}{lccc}
\hline & $\begin{array}{c}\text { Teste de Levene para igualdade de } \\
\text { variâncias (aceitamos } \mathrm{H}_{0} \text { ?) }\end{array}$ & $\begin{array}{c}\text { Teste-t para igualdade } \\
\text { de médias }\end{array}$ \\
\hline t-test (p-value) & Sim & t-test (p-value) \\
Destino da produção & 0,501 & Não & $0,000 * * *$ \\
Apoio de entidades governamentais & $0,001 * * *, 000 * * *$ \\
Que entidades apoiam & $0,000 * * *$ & Não & $0,000 * * *$ \\
Meios utilizados no cultivo & $0,000 * * *$ & Não & 0,163 \\
Origem do financiamento & $0,000 * * *$ & Não & $0,003 * *$ \\
Produtomais cultivado & $0,000 * * *$ & Não & $0,000 * * *$ \\
Produto com maior rendimento & $0,000 * * *$ & Não & 0,573 \\
Utilização de fertilizantes & $0,000 * * *$ & Não & $0,049 *$ \\
Local de aquisição de fertilizantes & $0,000 * * *$ & Não & $0,000 * * *$ \\
Conhecimento de fertilizantes orgânicos & $0,000 * * *$ & Não & $0,001 * *$
\end{tabular}

Nota: $\mathrm{H}_{0}=$ Igualdade de variâncias; ${ }^{*} \mathrm{p}<0.05 ; * * \mathrm{p}<0.01$ and $* * * \mathrm{p}<0.001$.

Em relação à existência ou não de diferenças significativas nas respostas médias, as EAE e as EAF não se distinguem apenas em três questões: meios utilizados no cultivo; produto com maior rendimento e se a agricultura é uma determinante 
do desenvolvimento. Note-se que, como foi visto atrás, ambas as entidades utilizam predominantemente meios manuais no cultivo da terra e procuram obter receitas no mercado por meio da produção de feijão e milho (as principais produções das EAE e das EAF).

Existem várias diferenças significativas nas respostas dadas pelas duas entidades e que será interessante analisar aqui. Por exemplo, em relação ao apoio por parte de entidades governamentais, as EAF não recebem praticamente nenhum apoio financeiro ou técnico, enquanto que, como foi referido, $93 \%$ das EAE recebem apoio da Direção Provincial da Agricultura e da Unaca, nomeadamente apoio em fertilizantes e administrativo. Relativamente ao investimento, componente importante pois é aquela que permitirá agregar valor à produção, observam-se diferenças entre as duas entidades, apesar dos fundos próprios serem a principal fonte de financiamento. Porventura, o ainda incipiente acesso por parte das EAE ao crédito bancário ou a outras fontes consegue criar diferença estatisticamente significativa entre as respostas.

Em relação à utilização de fertilizantes, há uma diferença entre as EAE e as EAF, embora quase não significativa. Em resultado da pobreza dos solos, a importância dos fertilizantes é inquestionável, pois a sua não utilização acarreta graves riscos para a produção. Assim, ambas as entidades tendem a utilizá-los, embora de forma menos preponderante nas EAF, porventura dadas as dificuldades na sua aquisição (acesso a pontos de venda e elevado custo). Relativamente ao local de aquisição, a diferença é significativa, com as EAE a adquirirem-nos no mercado formal (em alguns casos, de modo subvencionado), ao contrário das EAF que os adquirem no mercado informal. Também em relação à utilização de fertilizantes orgânicos verificam-se diferenças significativas, pois as EAE utilizam-nos mais habitualmente, o que é certamente explicado pelo fato de possuírem gado nas suas explorações, o que será mais difícil para as EAF. O nível de satisfação dos resultados obtidos nas campanhas agrícolas das EAE e EAF não será aquele ambicionado pelos seus membros. Tal pode-se verificar na questão colocada aos inquiridos sobre os níveis de satisfação da produção, sendo que $96 \%$ das EAE responderam que o grau de satisfação é razoável, a par de $80 \%$ nas EAF, diferença essa que se comprova no teste de igualdade de médias.

Com o propósito de se conhecerem as dificuldades sentidas pela população em estudo, foi questionada a origem da água, fator indispensável para a agricultura. 
Nessa questão, como foi visto atrás, $83 \%$ dos inquiridos das EAE responderam que as chuvas constituem a única fonte de água para o cultivo, impossibilitando-lhes a realização de cultivos em períodos de seca e de estiagem. Apenas $17 \%$ referem possuir alternativas à irregularidade das chuvas por meio das valas de drenagem. $\mathrm{O}$ mesmo acontece com as EAF, sendo que 55\% responderam que a chuva é a fonte de água por excelência e cerca de $41 \%$ possuemi, para além da água da chuva, valas de drenagem que servem de alternativa em períodos de seca e estiagem. Como vemos na Tabela 4, estas diferenças nas respostas são estatisticamente significativas.

\section{CONCLUSÕES}

O presente trabalho teve lugar num período em que a queda do preço do barril de petróleo afetou significativamente Angola, que durante o passado recente vinha aproveitando os preços elevados do petróleo, pois é o segundo maior exportador africano. Em Angola, têm sido muitas as vozes a favor de uma maior diversificação das receitas do Estado por forma a evitar a dependência das receitas petrolíferas e diamantíferas. Daí surge um papel a ser desempenhado pela agricultura empresarial e familiar, num país com forte potencial agrícola, onde são cultivados menos de $10 \%$ das terras aráveis disponíveis.

Em função do número de membros que compõem as EAE e EAF, o setor agrícola tem condições para cumprir um papel relevante no processo de desenvolvimento, com ocupação de mão de obra, criação de mercados e geração de receitas, sustentando as teorias que consideram a agricultura como podendo impulsionar o aparecimento de outros setores que contribuam para o crescimento e desenvolvimento econômicos.

Em síntese, enunciam-se os seguintes resultados:

i) a produção é maioritariamente orientada para o autoconsumo, sendo uma pequena parte da produção direcionada para o mercado informal. Isto significa que há um excedente capaz de suprir algumas necessidades de caráter financeiro das entidades, permitindo o seu crescimento. Preferencialmente, o destino principal será sempre o mercado informal, 
dadas as dificuldades encontradas em termos de acesso aos mercados formais (e.g., distância, licenciamento etc.), o que do ponto de vista do Estado é desvantajoso dada a perda ocorrida quanto à arrecadação de impostos. A criação de uma rede mais alargada e organizada de mercados rurais, que contrarie a simples venda junto das estradas, poderá ser uma opção interessante para incrementar as receitas provenientes do comércio; ii) as EAE são apoiadas pela DPADR em termos técnicos e na distribuição de fertilizantes, embora não de forma regular e nas quantidades desejáveis. Mesmo assim, os preços praticados são inferiores aos do mercado informal. Recebem igualmente apoio administrativo por parte da Unaca. Já as EAF apenas recebem $o$ apoio indireto das políticas governamentais criadas para o crescimento e desenvolvimento do setor, sendo difícil o apoio direto aos agricultores. A fragilidade dos serviços de extensão agrária e de assistência técnica é um fator muito negativo, que deveria merecer a atenção das entidades governamentais, nomeadamente, alargando-se as competências e capacidades do IDA;

iii) o nível acadêmico dos líderes das EAE e EAF é baixo, tendo frequentado na sua maioria apenas o ensino primário. Este é um fato extremamente negativo, pois a prática da agricultura solicita cada vez mais aos intervenientes técnicas sofisticadas que exigem literacia e atualização de conhecimentos; iv) o registro dos terrenos nas conservatórias é incipiente, se não mesmo nulo, o que representa um risco acentuado tanto para as EAE como para as EAF pelo fato de não existir qualquer garantia definitiva quanto à posse. No entanto, tanto as EAE como as EAF realizam as suas práticas em áreas adquiridas no âmbito do direito consuetudinário, o que de certo modo goza de uma relativa garantia, já que tal é reconhecido pelo direito angolano; v) os meios de trabalho utilizados na atividade agrícola são na sua maioria manuais ou a combinação de meios manuais e tração animal. Assim, as EAE tendem a combinar os dois meios, o que se justifica pela extensão de terra explorada, enquanto que as EAF utilizam na sua maioria apenas meios manuais;

vi) os fundos próprios constituem praticamente a única forma de 
financiamento de qualquer investimento. Este é um aspecto muito negativo num momento em que se espera muito da agricultura como motor da necessária diversificação da economia e da redução da dependência das importações de certos produtos que constituem a cesta básica;

vii) a utilização de fertilizantes é indiscutível, tanto para as EAE como para as EAF, em resultado da pobreza dos solos, no entanto, a questão do seu elevado preço é fundamental. Os fertilizantes são na sua maioria adquiridos no mercado informal a preços elevados, o que onera o processo agrícola. Estes preços elevados devem-se em parte à ausência de uma fábrica de produção de fertilizantes no país e à não existência de uma rede de distribuição comercial. Sendo o fornecimento de fertilizantes por parte do IDA insuficiente e irregular, a quantidade recebida pelas EAE torna-se insuficiente para cobrir toda a área cultivada, obrigando-as ao recurso ao mercado informal. Do lado das EAF, o recurso é a compra no mercado informal, pelo que, não recebendo qualquer tipo de subvenção, o seu proceso produtivo fica mais oneroso. A dinamização do crédito rural, a par de maior acessibilidade a pontos de venda de fertilizantes, poderia contribuir para a redução deste problema;

viii) a ausência de animais nas explorações das EAF constitui a principal razão para a fraca utilização de fertilizantes orgânicos. Também nesta questão o papel do crédito rural poderia ser relevante, permitindo a aquisição de cabeças de gado por parte das EAF;

ix) a única fonte de água para a prática agrícola é, para a maioria das entidades, a água das chuvas, o que estabelece um risco enorme em períodos de estiagem e de seca. $\mathrm{O}$ constrangimento provocado pela dependência da chuva poderá ser reduzido com a implementação de projetos de irrigação, mesmo de pequena escala mas que utlizem técnicas modernas de irrigação. Para além da chuva, a não utilização de tecnologias também constitui um fator que condiciona em determinadas circunstâncias o incremento da produção agrícola;

x) na sua generalidade, as EAE e as EAF são unânimes em considerar que uma agricultura assistida e apoiada com meios adequados para uma boa prática, bem como a redução dos preços dos fertilizantes, poderão constituir 
fatores capazes de impulsionar o surgimento de outros setores de atividade econômica, indispensáveis para catapultar a província do Huambo para um desenvolvimento sustentável e harmonioso.

Com base no número de pessoas que o setor agrícola incorpora, pode-se concluir que uma parte considerável da população deixa de estar desempregada devido ao papel que a agricultura desempenha ao proporcionar recursos para o desenvolvimento global da economia, dando um contributo progressivo e inevitável e constituindo a principal fonte de emprego em comunidades sobretudo rurais. Nesse sentido, o setor da agricultura continua a ser, em Angola e na província do Huambo em particular, o setor socialmente mais relevante.

Tendo em conta o contexto em que este trabalho foi realizado, nomeadamente num período em que as instituições governamentais se preocupam com a diversificação da economia que passa necessariamente pela maior participação do setor agrícola, haverá certamente alguns aspetos que poderão ser melhorados em trabalhos futuros de investigação, na expectativa de colocar sobre a mesa informação cabal que possa ser mais útil para as decisões políticas. Relativamente ao inquérito, futuras pesquisas poderão incorporar outras variáveis e aplicá-lo a outras regiões do país, procurando validar se a realidade aqui encontrada é extensível a todo o país.

\section{REFERÊNCIAS}

AVELÃS, A. J. Economia política: introdução à história da ciência económica e do pensamento económico. Coimbra, 1999. 2. vol. (SASUC - SERVIÇO DE TEXTOS).

BAIARDI, A.; ALENCAR, C. M. Agricultura familiar, seu interesse acadêmico, sua lógica constitutiva e sua resiliência no Brasil. Revista de Economia e Sociologia Rural, v. 52, n. 1, p. 45-62, 2014.

BANCO MUNDIAL. Relatório sobre o desenvolvimento Mundial 2008. USA: The World Bank, 2008.

CARVALHO, C.; SANTOS, A.; CARVALHO, G. Rede Brasil Rural: Inovação no contexto 
da agricultura familiar. Revista em Agronegócio e Meio Ambiente, v. 8, n. 1, p. 79-94, 2015.

CORIGE, M.; HENRIQUES, P. D.; CARVALHO, M. L. Constrangimentos no desenvolvimento da Agricultura no corredor do rio Dande: o caso de Santa BoleaTari, Bengo, Angola. Alimentar Mentalidades, Vencer a Crise Global - Atas do ESADR 2013, 15 a 19 de outubro de 2013, Évora, p. 609-633, 2013.

CUNGUARA, B.; GARRETT, J.; DONOVAN, C.; CÁSSIMO, C. O setor agrário e Moçambique: análise situacional, constrangimentos e oportunidades para o crescimento agrário. Maputo-Moçambique: Ministério da Agricultura. Direção de Economia, 2013. (Relatório de pesquisa 73p)

FAO. Fórum Global e Exposição sobre Agricultura Familiares - Resumo e Resultados. Organização das Nações Unidas para a Agricultura e Alimentação, 2014. Disponível em: < http://www.fao.org/family-farming2014/news/news/details-press$\mathrm{room} / \mathrm{pt} / \mathrm{c} / 218447>$.

FISCHER, A.; MARINI, D.; FILIPPIM, E. Perspectivas de agricultores familiares para a permanência na atividade rural. Revista ESPACIOS, v. 37, n. 7, p. 10, 2015.

GARCIA, A. A. Agricultura e desenvolvimento econômico no Brasil: os debates nas décadas de 50 a 70. Ensaios FEE, Porto Alegre, 1990.

GERRY, F. D. A problemática do desenvolvimento rural. Compêndio de Economia Regional, 2. ed. Coimbra: APDR, 2002. p. 548-552.

GUANZIROLI, C.; GUANZIROLI, T. Modernização da agricultura em Moçambique: determinantes da renda agrícola. Revista de Economia e Sociologia Rural, v. 53, n. 1, p. 115-128, 2015.

HARRIS, J. R.; TODARO, M. P. Migration, unemployment and development: a twosector analysis. American Economic Review, v. 60, n. 1, p. 126-142, 1970.

IDA. Relatórios Consolidados do Ano Agrícola 2009-2010/ 2010-2011/ 2011-2012 
e 2012-13. Instituto de Desenvolvimento Agrário, Angola - Huambo, vários anos.

JOHNSTON, B. F.; MELLOR, J. W. The role of agriculture in economic development. American Economic Review, v. 51, n. 4, p. 566-593, 1961.

LEWIS, W. A. Economic development with unlimited supplies of labour. The Manchester School, v. 22, n. 2, p. 139-191, 1954.

LUCENA, R. B.; SOUZA, N. O papel da agricultura no desenvolvimento econômico brasileiro, 1980-1998. Revista Análise Econômica, v. 19, n. 35, p. 55-72, 2001.

MADRP. Relatórios de Avaliação da Campanha Agrícola 2005-2006/ 2006-2007/ 2008-2009/ 2010-2011/ 2011-2012 e 2013-2014. Luanda, Angola: Ministério da Agricultura do Desenvolvimento Rural e das Pescas.

MARÔCO, J. Análise Estatística com o SPSS Statistics. 6. ed. Report Number Lisboa, 2015.

MBOMBA, M. G.; HENRIQUES, P. D.; REGO, M. C.; CARVALHO, M. L. S. O desenvolvimento rural e a redução da pobreza no Norte de Angola. Revista Angolana de Sociologia, n. 4, p. 67-86, 2009.

MOSCA, J. Agricultura e desenvolvimento em África. Lisboa: Instituto Piaget, 2008.

NOJIMA, D. Teoria do desenvolvimento e economia regional: Uma análise da experiência brasileira, 1995-2005. Tese (Doutorado) - Universidade Federal do Paraná. Curitiba, 2008.

PACHECO, F.; CARVALHO, M. L.; HENRIQUES, P. D. Contribuição para o debate sobre a sustentabilidade da agricultura angolana. Economia, Sociologia, Ambiente e Desenvolvimento Rural. Atas do $2^{\circ}$ Encontro Luso-Angolano na Universidade Metodista de Angola, Luanda, 6 a 8 de outubro 2011, p. 311-343, 2011.

PAIN, R.; ARRUDA, I. As características da experiência socialista na agricultura de Angola após independência. Cadernos de Pesquisa do CDHIS, v. 40, n. 22, p. 69- 
$78,2009$.

PINHEL, M. F. A importância do setor agrícola no desenvolvimento dos países ACP. Dissertação (Mestrado em Ciência Política e Relações Internacionais)

- Faculdade de Ciências Sociais e Humanas da Universidade Nova de Lisboa, 2012.

ROMEIRO, A. D. Agricultura sustentável, tecnologia e desenvolvimento rural. Agricultura Sustentável, Jaguarina, v. 3, n. 1/2, p. 34-42, 1996.

SHULTZ, T. W. Transforming traditional agriculture. Yale University Press, 1964.

Recebido em: 21 de março de 2016 Aceito em: 10 de outubro de 2016 